\title{
Superexploração do trabalho, espoliação urbana e crise do trabalho: notas a partir das estratégias de sobrevivência na periferia metropolitana de São Paulo
}

\author{
Overexploitation of labor, urban dispossession and labor crisis: notes from the \\ survival strategies in the metropolitan outskirts of São Paulo
}

Fernando Firmino Messias Mestre em Geografia Humana pela Universidade de São Paulo, Brasil fernando.messias@usp.br

\begin{abstract}
Resumo
A existência de uma parcela significativa da força de trabalho que se reproduz a partir das chamadas estratégias de sobrevivência na metrópole paulistana é posta neste texto como uma possibilidade de contribuir com o debate das periferias urbanas no contexto da modernização periférica brasileira. Aponta-se aqui a necessidade de compreender as periferias urbanas não apenas no contexto da superexploração do trabalho e de seus elos com a espoliação urbana, mas também, simultaneamente, a partir de uma crise do trabalho na contemporaneidade que constitui o fundamento da reprodução de variadas estratégias de sobrevivência da força de trabalho nas metrópoles brasileiras.
\end{abstract}

Palavras-chave: Periferias urbanas, modernização periférica, crise do trabalho.

\begin{abstract}
The existence of a significant portion of the workforce that is reproduced from calls survival strategies in the São Paulo's metropolis is putting in this text as a possibility to contribute to the debate in the context of urban peripheries of Brazilian's peripheral modernization. It's pointed out here the need to understand the urban peripheries not only in the context of exploitation of the work and its links with urban dispossession, but also, simultaneously, from a crisis of work in the contemporary world which is the basis of reproduction varied survival strategies of the labor force the Brazilian's metropolis.
\end{abstract}

Keywords: urban peripheries, peripheral modernization, labor crisis.

\section{INTRODUÇÃ̃}

Dentre os debates que procuraram compreender os processos econômicos determinantes na modernização do Brasil após meados do século XX, destaca-se, sob o terreno marxiano de análise, a teoria da dependência. Esta vertente do pensamento especificamente econômico debruçava-se sobre uma análise das relações de troca em nível global e compreendia a economia mundial assentada em relações baseadas na transferência do excedente dos países subdesenvolvidos para os desenvolvidos. Diferentemente destes últimos, os países chamados subdesenvolvidos possuiriam pouca margem de manobra diante das exigências colocadas por esta divisão do trabalho ao nível internacional, conforme aponta Marini (2011) e Amaral e Carcanholo (2009). No interior desta abordagem, o excedente econômico seria produzido nestes países não a partir da incorporação de padrões elevados de tecnologia, mas, sobretudo, por relações de trabalho específicas inerentes a esta 
condição de desenvolvimento, pautadas pela superexploração do trabalho; ou mesmo, em outras palavras, em uma ampliação da taxa de mais-valia na qual se assentariam os lucros das empresas.

Este texto tem como ponto de partida a superexploração do trabalho como um conceito central nas ciências sociais durante e após a década de 1970 e que a tiveram como fundamento da compreensão dos processos urbanos, mais especificamente da produção de periferias urbanas ${ }^{1}$. Assim, procura, em um primeiro momento, recuperar a leitura sobre a urbanização brasileira e sua estrita relação com as formas de ser do trabalho no cerne da modernização brasileira, compreendida sob o escopo da superexploração do trabalho, que culmina, por conseguinte, na espoliação urbana. A riqueza da vasta literatura, aqui sintetizada nas obras de autores como Camargo et al. (1982), Kowarick (1993; 1994) e Oliveira (2003), é trazida de modo a inserir questões que apontam o padrão espoliativo da reprodução da força de trabalho, a propósito das periferias urbanas das grandes metrópoles - mais particularmente São Paulo - no cerne da modernização brasileira e dos próprios limites do capital.

As páginas que se seguem procuram expor em linhas gerais esse debate e, em um segundo momento, a partir dele e da realidade trazida pelos nossos trabalhos de campo, abrir um caminho de interpretação baseada no que chamamos de crise do trabalho para se compreender os processos determinantes na produção das periferias urbanas na contemporaneidade. Trata-se de observar que, diante da modernização brasileira e da superexploração do trabalho que lhe é inerente, produzia-se uma significativa parcela da força de trabalho urbana que compunha um extenso exército industrial de reserva, que preferimos designar de sujeitos monetários sem dinheiro (KURZ,2004) no interior das diversas estratégias de sobrevivência por eles praticadas, compondo um mosaico de atividades nas periferias urbanas, comumente postas em relevo nas discussões sobre o circuito inferior da economia trazida por Santos (2002). As periferias urbanas, enquanto lócus da reprodução da força de trabalho, seriam capazes de apontar a espoliação urbana não assentada tão somente na superexploração do trabalho, mas também acenar para a necessidade de compreendê-las no interior de outros desdobramentos da negatividade do capital exposta por Marx na sua obra $O$ capital. Desta forma, procuramos traçar uma interpretação na qual as estratégias de sobrevivência trazidas nas seções finais compõem um elemento importante para acrescer ao debate a respeito das periferias urbanas, no interior de um processo ínsito à modernização e da urbanização que lhe é inerente: a crise do trabalho. 


\section{PERIFERIAS E ESPOLIAÇÃO URBANA: ELOS COM A SUPEREXPLORAÇÃO E A CRISE DO TRABALHO}

O debate intelectual no Brasil, centrado em compreender e fomentar o desenvolvimento capitalista nacional sob os pilares nacional-desenvolvimentistas, seguiu-se da urgente reflexão acerca das condições da exploração da força de trabalho. Desvelar as funções desta no cerne do processo produtivo se apresentava como fundamental para a compreensão da real dinâmica do desenvolvimento econômico nacional e de seu intrínseco alijamento da reprodução da força de trabalho no âmbito das mudanças qualitativas do padrão de acumulação registrado nesse período: o movimento de uma economia agrário-exportadora para a consolidação da urbano-industrial.

Diante da consolidação da indústria enquanto centro da acumulação de capital nacional, o crescimento acelerado da economia brasileira em meados do século $\mathrm{XX}$, com destaque para o momento posterior intitulado de Milagre Econômico, foi compreendido no bojo do incremento da produtividade do trabalho das empresas, ao passo que o rendimento do trabalhador abarcava cada vez menos este crescimento do produto interno bruto. Nas palavras de Camargo et al. (1982, p.64), “a elevação gradativa da produção interna, longe de significar uma melhoria generalizada das condições de vida da população, implicou em grande parte no reforço da capacidade de acumulação das empresas". Acrescentam, ainda, que

na medida em que a produção por trabalhador (produtividade do trabalho) cresceu, a partir de 1968, a taxas superiores a 5\% ao ano, enquanto o salário mínimo real evoluiu a taxas, via de regra, negativas, foi possível às empresas apropriarem-se da totalidade dos ganhos de produtividade obtidos, elevando dessa forma o nível do excedente gerado. (CAMARGO et al, 1982, p.64).

Assim, tendo em vista este contexto de baixos salários, as condições da reprodução da vida da força de trabalho em São Paulo, município que condensava grandes implicações do crescimento da indústria desse momento, chamava atenção para a relação da pobreza com o desenvolvimento industrial brasileiro. Dessa forma, a exposição da classe trabalhadora a situações precárias de vida na metrópole paulistana inseria o problema do salário dos trabalhadores urbanos incapaz de prover a própria reprodução destes, o que se conjugava à insuficiente oferta de bens de consumo coletivos no cerne de inúmeros debates (CAMARGO et al, 1982, KOWARICK, 1993). São Paulo, sendo em grande medida o lócus que permitia compreender o sentido da reprodução da força de trabalho no interior da modernização brasileira pela sua expressividade econômica em nível nacional e, consequentemente, pelo contingente de força de trabalho inserido nas atividades industriais, apontaria a consolidação do capitalismo periférico e seus elos com a má condição de vida dos trabalhadores, nos termos que Kowarick (1993) reconhece como espoliação urbana. 
O crescimento econômico do município de São Paulo, principalmente a partir da industrialização da década de 1950, bem como a expansão urbana a ele inerente, foi compreendido no bojo do dinamismo pautado na superexploração dos trabalhadores que, de acordo com Kowarick (1983), deixavam em evidência um "progresso apoiado na pauperização daqueles que leva[va]m adiante as engrenagens econômicas" (1983, p.56). Dessa forma, havia que se considerar um processo de urbanização em que a produção das periferias paulistanas se efetivava enquanto um momento pertinente à acumulação de capital industrial frente aos elos desta com a (re)produção da metrópole de São Paulo, assumindo, assim, esta produção e reprodução periféricas, a reposição do trabalho destinado a este processo. Estes espaços revelavam, até mesmo através de sua paisagem, os traços do modo de acumulação típico dos países de modernização tardia que "não transformou as drásticas condições de existência" (KOWARICK, 1983, p.57) de expressiva parcela da população trabalhadora. A autoconstrução aparece como um elemento onipresente nesses espaços da metrópole por se apresentar como a possível forma de o trabalhador resolver os problemas envolvidos no custo de habitação inalcançável pelo seu salário² ${ }^{2}$ MARICATO, 1982). Nessa direção, as formulações sobre a periferia urbana se efetivavam sobre a reflexão da relação basilar capital-trabalho específica da modernização brasileira, o que incluía expor o capital produtivo como determinante das definições dos espaços da metrópole. Assim, a periferia urbana, enquanto o espaço da força de trabalho no interior deste debate, era produzida para e pela reprodução do capital, ao dispor o trabalho necessário à efetividade deste movimento.

As leituras de Kowarick (1993; 2009), a respeito da constituição das periferias urbanas, pontuam as nuances do estabelecimento destes espaços produzidos a partir da necessária reprodução da força de trabalho em termos urbanos, que na realidade comporia a espacialização de processos pertinentes ao momento da modernização da metrópole. No início do desenvolvimento industrial nacional, que assumiu em São Paulo sua maior amplitude, incluía a expansão dos bairros dirigidos à moradia da classe trabalhadora. Já a partir dos anos 70, esta expansão é caracterizada pelo padrão periférico de ocupação do solo urbano, designação ao espraiamento dessas moradias em direção a inúmeros pontos da região posteriormente denominada de Grande São Paulo. Esta forma de reprodução da metrópole ocorria, sobretudo, pelo "próprio avanço da industrialização, que se espalhou por novos núcleos, seguindo os eixos ferroviários e, posteriormente, os rodoviários." (KOWARICK, 2009, p.26).

Assim, os termos em que se situava a análise das periferias urbanas paulistanas, no cerne da forma específica de relação do capital com trabalho na modernização brasileira - no caso, da superexploração do trabalho, base da expansão capitalista no país - foram dirigidos a compreender

\footnotetext{
${ }^{2}$ A abordagem de Maricato (1982) constitui um esforço de compreender a formação desse espaço específico que se conformava para e pela força de trabalho, no cerne de um processo que a autora intitula como proletarização do espaço, processo este que se intensifica com a industrialização da década de 50.
} 
um crescimento econômico específico, cujas bases estavam intimamente ligadas a um processo de expansão da economia em que se impossibilitava à força de trabalho a conquista das condições objetivas essenciais a sua reprodução na metrópole. De acordo com Oliveira (2003), possui um papel decisivo para este quadro histórico a disposição de um contingente extensivo de força de trabalho posto a esta industrialização nacional, bem como o estabelecimento da legislação trabalhista e a nova função assumida pela agricultura na economia brasileira.

Nessa direção, no que tange à legislação trabalhista, sob a leitura de Oliveira (2003), o salário mínimo se estabeleceria para manter um nível de remuneração inatingível sob a relação dos empregadores com os trabalhadores. A criação deste mínimo estava circunscrito à nova realidade que surgia, no qual a acumulação urbano-industrial era induzida e reforçada através de um imenso exército industrial de reserva e um nivelamento abaixo do real custo da força de trabalho regulamentado pela criação do salário mínimo. Por essa razão, com o estabelecimento da legislação trabalhista há um impulso à acumulação "caracterizando toda uma nova etapa de crescimento da economia brasileira" (2003, p.39), a partir da qual a regulação dos fatores capital e trabalho aparece como a forma necessária de se efetivar a transição da economia agroexportadora para a economia urbano-industrial. Nesse sentido, a dinâmica da agricultura assume a função, entre outras, de fornecer os bens de consumo com preços pertinentes ao baixo nível de renda dos trabalhadores urbanos.

Diante deste contexto, ao se detectar as formas precárias de reprodução da vida do trabalhador no contexto da espoliação urbana, foram amplas as leituras que buscavam promover a necessária mobilização da força de trabalho a respeito de seu espaço de moradia e de trabalho, conjugação que correspondeu ao mote de diversos movimentos ligados à esquerda (KOWARICK, 1994). Houve uma rica elaboração teórica sobre esse momento da constituição da periferia metropolitana e os processos nela envolvida, tributária dessa preocupação com a reconhecida espoliação urbana e a busca de emancipação social, da qual se derivaram os termos de uma luta de classes que se espraia do terreno fabril e visualizava na luta pela cidade o cerne do embate entre classes. De acordo com Bava

o conflito na fábrica ganha as ruas, encontra a solidariedade popular e, ao generalizar-se, lança o germe da organização popular nos bairros, o germe de movimentos populares que irão surgir a partir de 1980 e questionar a prefeitura, os órgãos públicos, exigindo água, luz, esgoto, asfalto, transportes, escolas, enfim, tudo aquilo que a espoliação urbana retira dos trabalhadores em favor do processo de acumulação capitalista. (BAVA, 1994, p.254).

O esforço teórico residia em compreender a condição assumida pelo grande contingente populacional que se dirigia às grandes cidades, debate em que não sem razão faria do morador ou “cidadão" categorias centrais da discussão (ARANTES, 2009), não significando o abandono do 
proletário, mas o reposicionamento do problema, haja vista uma realidade na qual, longe do trabalhador industrial compor a regra, o desdobramento do processo econômico denotava que as formas de inserção econômica da força de trabalho se davam em serviços diversos os quais correspondiam a estratégias de sobrevivência.

Erigia-se um debate a respeito da condição desse trabalhador enquanto morador da cidade que não oferece os bens de consumo indiretos cruciais a sua reprodução - no caso, o salário indireto, provido pelo Estado através do fundo público ${ }^{3}$. Apesar de nuances sobre esta questão, o fato é que, em linhas gerais, há a convergência do problema assentado em uma modernização periférica que, além de levar ao limite a exploração do trabalho, não assume os custos da reprodução da força de trabalho na forma do salário indireto. Marca, assim, um redimensionamento da luta de classes, pois a mesma incluiria questões em torno de bens inerentes à vida urbana, partindo, portanto, do morador-trabalhador da cidade em busca de serviços e de condições de vida que não lhe são ofertados.

Esta realidade urbana do capitalismo periférico não se efetivava com a presença maciça do proletário industrial, mas sim a partir de uma série de atividades designada de serviços nas quais expressiva parcela da força de trabalho encontrava a forma de inserção no mundo do trabalho. A perspectiva de Oliveira $(1997,2003)$ suscita a periferia da metrópole constituída, inclusive, enquanto lócus da moradia dos muitos trabalhadores que se inseriam nestas atividades diversas atividades estas, sublinhe-se, demandadas pela industrialização, as quais ficaram a cargo da própria organização desta enorme quantidade de força de trabalho mobilizada para e pela modernização nacional. Nas palavras de Oliveira, tal parcela dos serviços assumidos por parte significativa da força de trabalho estabelecida nas grandes cidades partia do

talento organizatório de milhares de pseudo-proprietários, que na verdade não estão mais que vendendo sua força de trabalho às unidades principais do sistema, mediadas por uma falsa propriedade que consiste numa operação de pôr fora dos custos internos de produção fabris a parcela correspondente aos serviços. (OLIVEIRA, 2003, p.68)

A magnitude deste extenso exército industrial de reserva, que se reproduzia muitas vezes a partir das atividades mencionadas por Oliveira, bem como suas condições de vida, se derivam da especificidade da inserção do Brasil na divisão internacional do trabalho a partir de meados do século XX. Isto significa que ambas as dimensões do exército industrial de reserva devem ser postas a luz das condições concretas do capitalismo em que se consolida o padrão industrial dependente. Isto porque, alega Marini (2011), o desenvolvimento destes países depende “menos das preferências

\footnotetext{
${ }^{3} \mathrm{O}$ salário indireto promovido através do fundo público está contido em uma discussão importante a respeito da desmercantilização da força de trabalho face às transformações da reprodução capitalista (OLIVEIRA, 1997; BURAWOY, 1990).
} 
que eles tenham e mais da dinâmica objetiva da acumulação de capital em escala mundial" (MARINI, 2011, p.168). Por essa razão, ao se inserir na divisão internacional do trabalho através de uma industrialização maciça da economia, os países dependentes verificaram, em linhas gerais, os desdobramentos inerentes ao desenvolvimento capitalista: "redução da população produtiva e crescimento das camadas sociais não produtivas" (MARINI, 2011, p.169). Todavia, "esses efeitos teriam de aparecer modificados pelas condições de produção próprias do capitalismo dependente." (ibidem).

Nessa direção, verificamos a necessidade de trazer à discussão elementos que contribuam na compreensão das particularidades em que se assenta a reprodução da força de trabalho nas grandes cidades brasileiras e que revelam alguns dos conteúdos sociais referentes às periferias urbanas no cerne da modernização específica do Brasil. O esforço que procuramos tecer neste texto repousa sobre a dimensão crítica do próprio processo de modernização periférica que engendra formas de ser do trabalho no bojo de uma crise inerente à reprodução do capital. Não se trata de alegar a inexistência desta exploração do trabalho levada ao limite, mas também de reconhecer a imanência da dimensão crítica que fundamenta o próprio processo a partir de outros desdobramentos. Sendo assim, queremos chamar atenção para o fato de que a industrialização na periferia do capitalismo teria como desdobramento a exposição da crise que lhe fundamenta, qual seja a dispensa de trabalho derivada da produtividade alcançada com o desenvolvimento das forças produtivas, conforme pontua a análise de Marini a propósito da diminuição da "redução da população produtiva" e da ampliação das “camadas sociais não produtivas". (MARINI, 2011, p.169).

Dessa forma, referir-se à periferia espoliada pela superexploração do trabalho inclui necessariamente expor um processo em que muitos dos indivíduos não são incorporados enquanto força de trabalho na acumulação capitalista no seu sentido substancial. Nessa direção, tornar-se-ia necessário identificar uma crise do trabalho que no Brasil se expressaria, inclusive, pela dispensa de trabalho, dispensa esta que foi muitas vezes obscurecida frente às dinâmicas de um crescimento econômico interpretado em grande medida por extenso exército industrial de reserva atuando como rebaixamento da remuneração à força de trabalho. A esse respeito, partindo do esgotamento do Milagre Econômico, KOWARICK (2009) identifica na passagem da década de 1970 para a de 1980 um marco do conteúdo deste momento do desenvolvimento capitalista nacional e sua expressão, na metrópole paulistana.

A mudança radical que se abre com os anos 1980 reside no fato de que, antes, a expansão econômica gerou uma quantidade de empregos que em certa medida contrabalançou a queda dos níveis de remuneração, ao passo que, com o avançar da década, não só se acentuou o grau de pauperização, como também muitos nem mesmo conseguem se transformar em mercadoria superexplorada por um capitalismo que se atola no pântano da recessão: no final de 1983, (...) o nível de emprego industrial voltou a ser semelhante ao 
imperante em 1973, num contexto em que continuou acentuado o incremento demográfico da Região. (KOWARICK, 2009, p.21, grifo nosso).

Kowarick identifica nesta asserção a dimensão do problema que devemos nos debruçar, pois, embora reconheçamos pertinência das relações de trabalho estabelecidas sob a perspectiva da superexploração da força de trabalho, verificamos a necessidade de refleti-las sobre a dimensão da negatividade do capital presente no seu movimento em seus amplos desdobramentos. Nesta perspectiva, reservamo-nos a compreender as inúmeras possibilidades criadas e recriadas pela força de trabalho destinadas a sua reprodução na metrópole, não em uma relação direta com a reprodução ampliada, mas como uma expressão de um processo de reprodução do capital assentado na negatividade do trabalho. Portanto, as mesmas devem ser vistas como a ação possível de uma parcela cada vez mais expressiva da população paulistana que, não possuindo perspectiva de ingresso ou retorno ao setor produtivo - mas que nem por isso escapa da forma monetária imposta pela lógica capitalista - procura, através de atividades diversas, recursos monetários orientados ao consumo daquilo que se impõe como necessário pelo mundo-mercadoria.

Ademais, a partir dessas atividades, põem-se em relevo questões importantes a respeito do conteúdo da reprodução social contemporânea. Seria possível alegar um momento no qual o capitalismo alcançou, nas palavras de Robert Kurz (2004, p.184), “seus limites e já não consegue integrar em sua lógica expressiva parcela da população mundial’? Tal questionamento possui ampla envergadura e o caminho que aqui expomos é uma primeira aproximação para compreender a reconhecida espoliação urbana não somente a partir da superexploração do trabalho, mas também pela crise do trabalho. Faz-se aqui um esforço inicial para interpretá-la sob este prisma, assumindo as dificuldades a que estamos sujeitos.

Passadas algumas décadas do período de intensificação da industrialização de São Paulo, um elemento que se apresenta como representativo deste processo da formação e reprodução periférica da metrópole na atualidade é a existência de inúmeras formas de ocupações cujo sentido é a reprodução dos indivíduos moradores nas próprias periferias. Desta maneira, reconhecemos que a periferia paulistana, no cerne de uma modernização periférica, não deve ser concebida como o lócus estrito da força de trabalho mobilizada à reprodução ampliada. As iniciativas que fazem uso da própria moradia, como os bares, as bombonieres e lanchonetes nos espaços da residência, bem como aquelas que usufruem do espaço da calçada e da rua para a venda de produtos variados, de preços sempre módicos, além dos serviços prestados à vizinhança, compõem importantes formas em que significativa parcela da força de trabalho insere-se no mundo do trabalho. O sentido destas atividades ocasionais na reprodução social constitui um dos elementos cruciais para o avanço da compreensão da periferia metropolitana e da dinâmica específica da modernização brasileira. 
Isso implica, pois, pôr sob outro prisma o problema da exploração da força de trabalho na metrópole de São Paulo. E é exatamente por constituírem em grande medida mais "estratégias de sobrevivência do que inserção produtiva”, como alega Pochmann et al (2000, p.13), que tais atividades nos levam a problematizar a própria periferia a partir das formas contingenciais em busca de algum ganho monetário. Através delas reconhecemos um momento em que o trabalho já "não chega a constituir sua positividade (...) como fonte viva do valor" (DAMIANI, 2004, p.28), sendo elas expressão da crise pela qual este texto procura chamar atenção para se compreender os processos urbanos contemporâneos, mais especificamente àqueles envoltos à reprodução da força de trabalho nas metrópoles.

Em suma, lançando mão destes pressupostos, esta modernização periférica brasileira teria como específica a si o fato do salário indireto compor uma proporção diminuta frente à necessidade da reprodução da força de trabalho, diante de um imensurável exército industrial de reserva. Em outras palavras, prover a totalidade da força de trabalho moradora das cidades dos bens de consumo coletivos necessários a sua reprodução mostrava-se inviável na condição própria da modernização do Brasil. Nesse ponto, remetendo à produção intelectual da década de 70, especificamente de Lucio Kowarick e seus interlocutores, Arantes (2009, p.119) alega que o urbano periférico nessas formulações aparece como “a negação da reprodução de trabalho em patamares aceitáveis"; "é, pois, sua dilapidação de forma espoliativa". Partindo da potência que esta asserção de Arantes a respeito de Kowarick traz, as periferias urbanas paulistanas contemporâneas resguardariam ainda o sentido desta modernização brasileira nos termos de um exército industrial de reserva reproduzido ao limite? As respostas a esta questão não são possíveis de serem trazidas na neste texto. Ademais, demanda uma extensa agenda de pesquisa que se fomente na construção de um conhecimento crítico desta realidade sob o espectro das especificidades da modernização e da urbanização brasileiras. Nessas páginas procura-se estabelecer um primeiro passo para contribuir nessa direção buscando uma aproximação com dinâmicas contemporâneas a propósito da reprodução da força de trabalho na maior cidade do país. Neste ponto, trata-se de reconhecer que a modernização brasileira traz consigo a produção de um contingente cada vez mais expressivo de indivíduos inseridos negativamente no mundo do trabalho: os sujeitos monetários sem dinheiro, designação de Robert Kurz nos marcos da crise do trabalho.

Nessa direção, procuramos expor uma aproximação com a Vila Nova Esperança, comunidade localizada entre os municípios de São Paulo e Taboão da Serra, como uma das possibilidades, entre tantas outras, de considerar, em alguma medida, a crise do trabalho. Verificase a reiteração das periferias da espoliação urbana, mas que, como procuramos abrir caminhos para esta discussão, não apenas fundamentada pela superexploração do trabalho, mas também pela reprodução de força de trabalho marcada por estratégias de sobrevivência que se conjugam com as 
precárias condições de vida na metrópole de São Paulo através de atividades ocasionais. Portanto, as notas que se seguem tratam de uma dimensão dos amplos processos de (re)produção das periferias urbanas no cerne do que compreendemos como crise do trabalho, exigindo investigações futuras a respeito de suas nuances e desdobramentos.

\section{ESTRATÉGIAS DE SOBREVIVÊNCIA NA PERIFERIA: CRISE DO TRABALHO A PARTIR DA VILA NOVA ESPERANÇA}

Passadas mais de três décadas desde o início do debate a respeito da espoliação urbana, a Vila Nova Esperança, no tocante a sua morfologia, se apresenta como a reiteração das periferias que serviam ao debate envolto às precárias condições do morador e trabalhador na metrópole e sujeito à espoliação urbana. Encravada em um terreno íngreme, com ruas tortuosas e com asfalto improvisado, conforma-se nos limites dos municípios de São Paulo e Taboão da Serra. O número total de moradores é impreciso, no entanto consta-se que corresponde a cerca de 500 famílias em meados de $2012^{4}$. Há o atendimento por uma linha de ônibus duas vezes ao dia: às 7 e às 17 horas. Isso significa a quase sempre necessidade de caminhar cerca de um quilômetro e meio para se chegar ao ponto de ônibus mais próximo, no Jardim João XXIII. A instalação de equipamentos urbanos, como lombadas e o próprio ponto de ônibus, surgiram da iniciativa dos moradores. Serviços de creches, escolas e postos de saúde são sanados apenas fora das suas mediações. O fornecimento formal de água data de 2004, embora não seja acompanhado de coleta de esgoto. Energia elétrica se apresenta como um problema cotidiano, pois seu provimento se dá através de gatos que percorrem, ao menos, cerca de um quilômetro de distância. Em relação ao lixo, devido às condições do arruamento, sua coleta não é realizada pelo caminhão, ficando à disposição dos moradores três caçambas insuficientes para o total de famílias; por essa razão, as mesmas estão sempre transbordando. Em relação às casas nela presentes, verificamos autoconstruções, desde as moradias elaboradas com madeira e materiais reutilizados diversos, àquelas levantadas com tijolos e concretos ${ }^{5}$.

Os moradores da Vila Nova Esperança apresentam algumas estratégias de sobrevivência que se constituem como a forma possível de inserção econômica diante dos termos da crise do trabalho e das condições urbanas precárias no tocante a serviços urbanos básicos. Nela encontramos

\footnotetext{
${ }^{4}$ Trata-se de um número que certamente se aproxima com a realidade. A dificuldade de precisar este número se deve ao fato do total de famílias se alterar com certa constância e não haver a possibilidade desse controle, conforme alegou a líder da Associação dos Moradores.

${ }^{5}$ Estas diferenças revelam níveis distintos no interior da reprodução desta força de trabalho na metrópole. No geral, o tempo em que residem no local auxilia na ampliação de suas casas; quanto maior o tempo, mais dinheiro dos familiares destinado à casa. Além do tempo para contribuir na ampliação da residência, o aumento dos números dos familiares, desde o casamento de filhos à chegada de parentes de outros estados, aparece como uma necessidade para expansão da casa, sobretudo com a construção de novos pisos.
} 
estratégias comuns a muitos moradores de porções pobres de São Paulo e de muitas metrópoles brasileiras que visam à aquisição módicas quantias de dinheiro, dinheiro este assumindo a condição de meio de pagamento. Estas serão expressas nos próximos parágrafos. Mas também encontramos uma relação econômica específica a esta comunidade, assentada na monetarização dos gatos, cujos fundamentos reportam à urbanização crítica em que a reprodução da força de trabalho se concretiza na metrópole paulistana. Nesta relação, a potência do dinheiro como mediador social, mesmo diante de sua ausência, deve ser objeto de discussão na última seção deste texto.

Muitos dos moradores da Vila Nova Esperança possuem elos com a circulação monetária no seguinte sentido: realizam atividades que surgem, em grande medida, enquanto comércios e prestações de serviços gerais, sobretudo em casas de famílias, que são conjugados, muitas vezes, a expedientes formais em empresas terceirizadas de portaria e de segurança. A maioria dos entrevistados é nordestina, cuja vinda a São Paulo ocorreu, sobretudo, na década de 1980.

O comércio local aparece como a forma de alguns dos moradores terem acesso ao dinheiro e mostra que, frente à crise do trabalho, estes indivíduos foram constantemente recriando formas de sobrevivência cujo norte sempre foi a retenção de alguma parcela da riqueza na sua forma monetária. O exemplo de Vitória, moradora da Comunidade desde 1996, aponta esta questão. Chegando a São Paulo, em 1993, passou a trabalhar num comércio de material escolar. Quando se viu desempregada após dois anos e, consequentemente, endividada, só lhe restava, segundo suas palavras, utilizar o seu conhecimento acerca da produção de artesanato adquirido quando vivia no estado da Bahia, pois já estava a um tempo significativo à procura de emprego. A partir do momento em que seu "negócio foi para frente", de acordo com seu relato, Vitória recebeu convites para trabalhar diretamente em alguns estabelecimentos, mas recusou todos, pois via no "trabalho por conta" inúmeras vantagens comparadas ao "trabalho registrado", pois este remete à incerteza de estar empregado ou não no dia seguinte, enquanto que com aquele era possível vender seus produtos, em momentos de grande procura, a vários estabelecimentos, bem como lhe oferecia $\mathrm{o}$ conforto de trabalhar em casa. Quando quitou suas dívidas, passou a investir na estrutura de sua casa, ampliando-a verticalmente, e fez da parte inferior da residência uma mercearia na qual seu esposo, desempregado desde muito tempo, passou a destinar dedicação integral a uma nova possibilidade de ampliar a renda familiar.

É importante observar no relato oferecido por Vitória que as formas de reposição desta sociedade estabelecem a afirmação do trabalho sob diversos aspectos. A maneira pela qual Vitória concebe o trabalho sintetiza em grande medida aqueles que incorporam o trabalho nas suas formas que são inerentes neste momento; por isso, o suposto ato empreendedor, o trabalho para si, surge como a possibilidade de inserção econômica frente aos termos da reprodução do capitalismo 
contemporâneo ${ }^{6}$. São sobre estes limites que o empreendedorismo desponta como uma aparente solução à crise do trabalho.

Desde 1982, quando se mudou para São Paulo, as ocupações de Maria do Amparo, que trabalhou duas vezes em empresas de confecção de roupas, denotam um dos caminhos possíveis a essa parcela social que deve buscar os mais diversos expedientes para inserção econômica. Após a sua demissão entre 1987 e 1988 dessas empresas, não conseguiu mais se inserir no mercado de trabalho a não ser no serviço doméstico. Atualmente trabalha sábados e domingos como acompanhante de uma senhora que reside em Moema e tem procurado outras casas de famílias para trabalhar durante os dias úteis. O exemplo de Maria do Amparo é reiterado por inúmeras mulheres na comunidade que encontram mecanismos para adquirir dinheiro através do serviço doméstico em outras famílias, sendo os serviços como diaristas uma das faces mais predominantes, e também flexíveis, desta prestação de serviço na atualidade.

Rosana, moradora do bairro desde a década de 90, sempre buscou meios para auxiliar na renda familiar a partir da própria casa, pois o que seu marido adquire como auxiliar de serviços gerais não é suficiente para a reprodução familiar. Antes conhecida como a quitandeira local, passou de um momento para outro a ser a cabeleireira, para o espanto inclusive dos moradores que nos acompanhavam na apresentação da Comunidade e não possuíam ciência desta mudança. "Frutas e verduras estragam muito rápido e tem muito prejuízo", alegou a senhora sobre a mudança repentina de sua ocupação. Todavia, como ela própria relatou, as dificuldades com a venda de produtos perecíveis saíram de cena para dar lugar às constantes faltas de luz que afligem a comunidade, pois os "gatos", única forma de dispor os moradores de energia elétrica, não garantem energia elétrica de forma ininterrupta, o que culmina, muitas vezes, na suspensão da prestação dos seus serviços ${ }^{7}$.

Todas essas formas de ser da chamada informalidade - as quais são manifestações da universalidade da forma-mercadoria - correspondem a uma maneira de incorporar quantias monetárias dirigidas à reprodução familiar. Diante da superexploração ou crise do trabalho são, portanto, as possibilidades da entrada destes indivíduos no mundo do consumo, que correspondem à forma pela qual a reprodução social se repõe nos termos atuais. Estas ocupações ocasionais não podem ser restringidas apenas à Comunidade aqui apresentada, pois, diante da diversidade pela qual a força de trabalho se repõe em uma metrópole como São Paulo, revelam a condição reiterada de indivíduos inseridos numa sociabilidade posta à circulação da riqueza abstrata, cuja determinação

\footnotetext{
${ }^{6}$ A análise de Davis (2006) a respeito do capitalismo contemporâneo e das condições de reprodução desta força de trabalho nas grandes metrópoles, faz menção a uma massa permanentemente supérflua ou humanidade excedente para suscitar a magnitude, dentro nos limites deste texto, do problema que procuramos discernir.

${ }^{7}$ A questão dos gatos compõe a última seção deste texto.
} 
da sua forma-monetária nos aparece como elemento fundamental nos dias atuais ${ }^{8}$. Portanto, o improviso nestas condições apresenta-se como a forma possível de inserção econômica que, não raro, se redefine subitamente na generalização da crise do trabalho.

Tendo em vista a circulação do capital e a sua predominância sob a forma-monetária, reconhecemos que resta a estes indivíduos, sejam aqueles cuja renda é insuficiente à reprodução ou que já não possuiriam valor de troca nesta sociabilidade, captar dinheiro através de subterfúgios próprios, fato que na realidade possui a sua determinação na crítica reprodução capitalista contemporânea. Fazemos referência ao termo crítico para qualificar a sociedade capitalista contemporânea fomentando-nos de um debate amplo que se estende pela tradição marxista (KURZ, 2004, 1997; MANDEL, 1982; SWEEZY, 1973) e que põe em relevo uma crise imanente no interior das relações fundantes do capitalismo.

A complexidade da crise capitalista contida na obra dos autores baseia-se na interpretação realizada entorno da queda tendencial da taxa de lucro e seus desdobramentos na sociedade capitalista, em que pesem as diferenças das abordagens e suas divergências. Baseados nessas leituras marxianas, chegamos à crise do trabalho como uma dimensão contida no próprio capitalismo, cujo desdobramento pode ser ilustrado por um contingente de força de trabalho estabelecendo nesta economia urbano-industrial através das estratégias de sobrevivência.

Por esta razão, verificamos que a busca cotidiana, ocasional e constantemente recriada para obtenção de dinheiro na periferia de São Paulo pode trazer elementos para enriquecer a compreensão do processo econômico em sua relação estrita com a reprodução da força de trabalho nas metrópoles brasileiras. Como procuramos expor nos parágrafos anteriores, o movimento do capital sugere constantes readequações no âmbito da própria reprodução da condição de sujeitos monetários sem dinheiro. A próxima seção trará uma dinâmica específica apresentada pelo nosso trabalho de campo capaz de trazer alguns refinamentos na compreensão da reprodução dessa força de trabalho na contemporaneidade.

\section{GATO DO GATO E URBANIZAÇÃO CRÍTICA}

O que desejamos expor em linhas gerais nesta seção refere-se ao âmbito de uma inserção econômica específica dos moradores da Comunidade. Acreditamos que esta possa contribuir na construção de nossa interpretação a respeito da lógica em que se assenta a reprodução social crítica tendo como ponto de partida este fragmento da metrópole de São Paulo na atualidade.

\footnotetext{
${ }^{8}$ Telles (2009) elenca com grande riqueza analítica uma série de atividades que compõem as estratégias de sobrevivência na contemporaneidade nas periferias urbanas. Sua análise percorre o fundamento de tais atividades como expansão ampliada do capital e abre um caminho para um amplo e necessário debate sobre o mesmo, conforme este texto procura brevemente apontar.
} 
Procuraremos discorrer nos parágrafos a seguir sobre uma das formas em que alguns dos moradores da Comunidade inserem-se economicamente e que ilustra a potência do termo sujeitos monetários sem dinheiro de Kurz (2004), trazendo em alguma medida a amplitude formal assumida pela crise do trabalho nas relações estabelecidas através da metrópole em sua reprodução e condição periférica e espoliativa.

Diante da não chegada da energia elétrica, os moradores da Vila Nova Esperança criaram instalações ilegais, os chamados "gatos" para suas casas ${ }^{9}$. Chama atenção que a constituição de redes para o fornecimento de energia elétrica se fez através de inúmeras articulações, compondo inclusive um "mercado" específico a partir dos gatos e da eletricidade frente ao não atendimento formal da mesma.

Para usufruir de um gato, exige-se mão de obra, bem como os dispêndios que a mesma demanda; assim, alguns moradores da Vila prestam serviços constantes devido às instalações e sua manutenção. Estes se especializam nas demandas dos serviços elétricos, sempre deflagradas devido à escassez e à precariedade com que a rede é instalada. Muitos deles sobrevivem de bicos, sendo estes realizadas no bairro um dos mais importantes para o orçamento da maioria deles. Geralmente, o eletricista que instalou o gato fica responsável pela sua manutenção e será sempre acionado em situações de interrupção ou queda da intensidade do fornecimento. Embora esta instabilidade se deva à própria condição das instalações, o fato é que ela é incitada muitas vezes graças aos gatos que se fazem nos gatos, o que torna recorrente o serviço dos eletricistas da Comunidade.

Isto ocorre porque o dispêndio necessário à aquisição de energia elétrica é alto e faz com que algumas famílias não o possam sanar. Por essa razão ocorre o fato mencionado: algumas famílias procuram obter energia das instalações realizadas por terceiros, o que reduz sobremaneira sua intensidade, já comprometida pela precariedade da transmissão possível nos termos em que se encontra a Comunidade. A partir daí surge a necessidade de averiguar as prováveis ligações indevidas, necessitando dos serviços dos eletricistas para a busca dos gatos realizados sem o consentimento de seu dono.

Ressalte-se que muitos gatos são coletivos, uma vez que algumas casas se unem para pagar o custo da sua instalação e manutenção. Em alguns casos, é necessário mais de um gato para suprir a necessidade de energia elétrica da casa, pois alguns são exclusivos apenas para lâmpadas, dada sua capacidade de transmissão. Somente aqueles que transmitem em quantidade maior eletricidade é que podem ser utilizados para geladeiras e chuveiro elétrico.

\footnotetext{
${ }^{9} \mathrm{O}$ fornecimento formal de energia elétrica pela Eletropaulo não se faz ainda, apesar de todas as mobilizações da Comunidade, devido aos conflitos judiciais em relação à área. Após acidentes com as ligações elétricas informais, chegando até mesmo à morte de um morador no início de 2011, a reivindicação por energia elétrica se tornou um das razões para inúmeros protestos da Associação dos moradores. Até a realização de nossos trabalhos de campo em 2013, o impasse a este respeito se mantém.
} 
Nesse contexto, a energia elétrica torna-se uma moeda de troca, sendo um exemplo comum a função que a mesma adquire no pagamento de aluguel através da concessão de uso de instalações. A família que, por ter improvisado a garagem para a mercearia, concede luz ao vizinho para usufruir da garagem. Neste caso trata-se de luz para lâmpadas, cabendo em relações de troca mais expressivas, como o desfrute de uma casa, o equivalente de um gato para geladeira e chuveiro.

A condição assumida por tais instalações elétricas na Vila Nova Esperança nos remete à necessária função do dinheiro na sociedade capitalista. Se o dinheiro constitui-se em um momento do desdobramento da contradição no interior da mercadoria ${ }^{10}$, verificamos que, em se tratando de um momento de generalização do que chamamos de crise do trabalho, nas condições urbanas engendradas pela modernização periférica brasileira, elementos cotidianos com a função de equivalente geral pode eclodir em determinados contextos sociais, como no caso da energia elétrica na Vila Nova Esperança ${ }^{11}$. Desta função de equivalente, que na exposição de Marx se revela como uma necessidade posta na lógica imante à própria mercadoria, qual seja a de permitir a generalização da troca, é possível deduzir a forma dinheiro, que se atrela não necessariamente ao dinheiro impresso em se tratando de momentos da reprodução crítica da força de trabalho. Por essa razão, a medida de valor, diante de sua crise, se realiza sob os mais distintos meios. Nessa direção, Rocha (2000) expôs esta função assumida pelos passes de ônibus, que, como os gatos aqui apresentados, despontam em múltiplas situações de sujeitos monetários sem dinheiro, pois a escassez de dinheiro não significa sua supressão enquanto mediador no cerne da consciência monetária não superada. Isso significa que no caso específico aqui apontado, o trabalho contido nos gatos é posto em uma média que deve mediar trocas, efetivando assim uma forma possível de realizar a sociabilidade pelo valor, negativamente.

Por essa razão, o improviso na Vila Nova Esperança, para além de mostrar a espontaneidade e a criatividade dessa sociedade, revela seus limites e as determinações críticas com as quais o suposto espontâneo e imprevisto estão atrelados. É importante reconhecer que essa urbanização, traduzida pela ausência do urbano, ou urbanização crítica nas palavras de Damiani (2008), cria uma dinâmica particular, embora não se possa perder de vista que a mesma está imersa no mundo mercadoria e na sua forma monetária. A consciência monetarizada está posta e alcança relações que não fazem uso concreto do dinheiro, o que pode ser observado pela equivalência pressuposta nas trocas de supostos favores e serviços. A construção dos dois circuitos da economia empreendida por Santos (2004) procura abarcar essa dinâmica da reprodução dos pobres,

\footnotetext{
${ }^{10}$ Marx (1988) procurou o sentido lógico da forma dinheiro a partir das relações de troca tendo como pressuposto um percurso no qual as relações de valor das mercadorias, desde a mais simples à mais acabada - ou melhor, da forma simples à forma dinheiro -, se impõem como uma necessidade derivada de uma oposição interna à própria mercadoria.

${ }^{11}$ Há, portanto, na relação M-M', correspondente às trocas entre usufruto da energia e outros serviços uma mediação abstrata, assumida por uma forma equivalente, que não se pode perder de vista na situação em questão. Nosso texto procura apontar um momento das formas possíveis em que se assumem tais relações.
} 
compreendida por Serpa (2011, p.102) como um "circuito econômico não moderno, que engloba a pequena produção manufatureira, o pequeno comércio e a multiplicidade de serviços de toda espécie." Os caminhos traçados neste texto procuram realizar uma abordagem distinta acerca das relações de sobrevivência enquanto não modernas, haja vista que estão inseridas no mundo mercadoria e são por ele determinadas, em que pesem suas diferentes formas de ser.

A respeito da compreensão que se faz das dinâmicas sociais dos pobres na cidade através da categoria centralidades vividas, Serpa (2011, p.105) assevera que “(...) é preciso reconhecer os lugares populares das metrópoles como centrais para o cotidiano e a vida, desfazendo paulatinamente a ideia de uma hierarquia de centros e assumindo o princípio de que todos os lugares são centralidades potenciais e merecem destaque na produção do conhecimento geográfico". Todavia, embora este texto reconheça a importância da busca do cotidiano e das diferenças por compor um momento importante ao desvendamento da realidade social, tal interpretação não se basta para alcançar a dimensão que julgamos necessário realçar. Por essa razão, procuramos expor aqui a luta pela sobrevivência, nas amplas formas por ela assumidas, como uma possibilidade de revelar a reprodução capitalista nos termos da crise do trabalho.

\section{CONSIDERAÇÕES FINAIS}

Este texto procurou recuperar em alguma medida a riqueza do debate em torno da espoliação urbana e inserir uma dimensão que o próprio processo de reprodução capitalista produz, reconhecida aqui como a crise do trabalho. Ínsita ao processo de industrialização brasileiro nas suas múltiplas especificidades e desdobramentos, esta crise do trabalho estaria inculcada no próprio processo de modernização periférica, o que pode ser vislumbrado não apenas na superexploração do trabalho, desvelada pela teoria da dependência, mas também nas estratégias daqueles que não se põem à valorização do valor, no sentido da exploração de mais-valia no produtivo, conformando o que Kurz (2004) designa de sujeitos monetários sem dinheiro. Sob este prisma, trouxemos uma dimensão da realidade capaz de apresentar elementos para um caminho que redimensione alguns dos termos aos quais se situa a compreensão das periferias urbanas nas grandes metrópoles brasileiras na contemporaneidade. Nessa direção, a Vila Nova Esperança nos revelou a necessidade de uma aproximação com as práticas envoltas à reprodução e ao cotidiano da força de trabalho nas periferias das metrópoles brasileiras, de modo a refinar as considerações em busca dos desdobramentos de uma modernização periférica. 


\section{REFERÊNCIAS}

AMARAL, Marisa Silva; CARCANHOLO, Marcelo Dias. A superexploração do trabalho em economias periféricas dependentes. In: Revista Kátal, Florianópolis, v.12, n.2, pg. 216-225. Jul/Dez 2009.

ARANTES, Pedro Fiori. Em busca do urbano: marxistas e a cidade de São Paulo nos anos de 1970. São Paulo: Novos Estudos CEBRAP, nº 83, pg.103-127, Mar/2009.

BAVA. Silvio Caccia. A luta nos bairros e a luta sindical. In: KOWARICK, Lúcio (org). As Lutas Sociais e a Cidade. Rio de Janeiro: Ed. Paz e Terra, 1994, p. 253-278.

BURAWOY, M. A Transformação dos regimes fabris no Capitalismo Avançado. In Revista de Ciências Sociais, São Paulo, V.5, nº 13, ano 5 (jun.) 1990, p.29-50.

CARMARGO, C. P. F et al. São Paulo 1975: Crescimento e pobreza. São Paulo: Editora Loyola, 1982, 155p.

DAMIANI, Amélia Damiani. Urbanização Crítica e Situação Geográfica a partir da metrópole de São Paulo. In: CARLOS, Ana Fani; OLIVEIRA, Ariovaldo Umbelino de. (org). Representações e crise da Metrópole. Vol 1. São Paulo, Contexto, 2004, p.19-58.

DAMIANI, Amélia Damiani. Espaço e Geografia: Observações de método da obra de Henri Lefebvre e a Geografia. Ensaio sobre Geografia Urbana a partir da Metrópole de São Paulo. Tese de Livre Docência em Geografia Humana. FFLCH-USP, São Paulo, 2008.

DAVIS, Mike. Planeta Favela. São Paulo: Boitempo, 2006, 272 p.

FURTADO, Celso. Desenvolvimento e Subdesenvolvimento. Rio de Janeiro: Editora Contraponto, 2009, 234p.

KOWARICK, Lucio. Lutas urbanas e movimentos populares: alguns pontos para reflexão. In: Espaço e Debates, nº, 1983 , p.55-63.

KOWARICK, Lucio. A espoliação Urbana. São Paulo: Editora Paz e Terra, 1993, 204p.

KOWARICK, Lucio. (org). As Lutas Sociais e a Cidade. Rio de Janeiro: Editora.Paz e Terra, 1994, 316p.

KOWARICK, Lucio. Escritos Urbanos. São Paulo: Editora 34, 2009, 143p.

KOWARICK, Lúcio; CAMPANÁRIO, Milton A. São Paulo, metrópole do subdesenvolvimento industrializado: do milagre à crise econômica. In: KOWARICK, Lúcio (org). As Lutas Sociais e a Cidade. Rio de Janeiro: Editora Paz e Terra, 1994, p. 53-72.

KURZ, Robert. O colapso da modernização. São Paulo: Editora Paz e Terra, 2004, 244 p.

KURZ, Robert. Os últimos combates. Petrópolis: Editora Vozes, 1997, 394 p.

MANDEL, Ernest. O capitalismo tardio. São Paulo: Editora Abril, 1982, 417 p.

MARICATO, Ermínia. Autoconstrução, a arquitetura possível. In:

A Produção

Capitalista da Casa (e da Cidade). São Paulo: Editora Alfa-Omega, 1982, p. 71-93. 
MARICATO, Ermínia. Metrópole na Periferia do Capitalismo. Ilegalidade, desigualdade e violência. São Paulo: Editora Hucitec, 1996, 141p.

MARINI, Ruy. Dialética da dependência. In: TRASPADINI, Roberta; STEDILLE, João Pedro. Ruy Mauro Marini - Vida e Obra. São Paulo: Editora Expressão Popular, 2011, $2^{\mathrm{a}}$ edição, pg. 131172.

MARX, Karl. O Capital - Crítica da Economia Política. São Paulo: Nova Cultural, Vol.1, 1988, $255 \mathrm{p}$.

OLIVEIRA, Francisco de. Crítica à razão dualista - O ornitorrinco. São Paulo: Boitempo Editorial. 2003, 150 p.

OLIVEIRA, Francisco de. Os direitos do antivalor. A economia política da hegemonia imperfeita. Petrópolis: Editora Vozes, 1997, 231p.

POCHMANN, Márcio; KJELD, Jacobi, SINGER, Paul. Mapa do trabalho informal - Perfil socioeconômico dos trabalhadores informais na cidade de São Paulo. São Paulo: Perseu Abramo, 2000, 64p.

ROCHA, Alexandre Souza de. Centralidade e periferia na Grande São Paulo: abordagem crítica sobre o morar na periferia da metrópole. Dissertação de mestrado apresentada ao departamento de Geografia da FFLCH, USP, São Paulo, 2000.

SANTOS, Milton. O Espaço dividido: os dois circuitos da economia urbana nos países subdesenvolvidos. São Paulo: EDUSP, 2004, 433p.

SERPA, Angelo. Lugar e centralidade em um contexto metropolitano. In: CARLOS, Ana Fani Alessandri; SOUZA, Marcelo Lopes; SPOSITO, Maria Encarnação Beltrão. (ORG.). A Produção do Espaço Urbano. Agentes e processos, escalas e desafio. São Paulo: Editora Contexto, 2011, p. 97-108.

SWEEZY, Paul. Teoria do desenvolvimento capitalista. Rio de Janeiro: Zahar editores, 1973, 288p.

TELLES, Vera da Silva. Ilegalismos urbanos e a cidade. Novos estudos Cebrap. №84, p 153-173. jul. 2009. 